\title{
Rare Types of Relation Between the Sciatic Nerve and the Piriformis Muscle
}

\author{
By \\ Kinziro Kubota, Isoo Noguchi and Takeo Nakano \\ Anatomy Department, Tokyo Medical and Dental University, Tokyo
}

The relation of the sciatic nerve to the piriformis muscle has already been studied statistically by many workers such as A d a c hi, Koganei et al, Miura, Yamagishi, Igarashi, Beaton, $\mathrm{Ku}$ shida, Hashimoto et al, Sugi y a ma, Kobata, Hay a ma and $\mathrm{O} u \mathrm{ti}$. As well known in the statistical data reported previously by these workers on this subject, the relation of the sciatic nerve to the piriformis muscle can be classified into three types as follows: 1. The sciatic nerve from the pelvis passes through the infrapiriformis foramen just below the piriformis muscle. 2. The peroneal portion of the sciatic nerve goes through the piriformis. 3. The peroneal portion of the sciatic nerve from the pelvis passes through the suprapiriformis foramen above the upper border of the piriformis muscle. Beaton has suggested a probability that the sciatic nerve may pass out of the pelvic cavity through the suprapiriformis foramen above the upper border of the piriformis. With regard to cases in Item 3,38 cases have been reported to date, as shown in the table. We had an oportunity to observe 5 cases of the third type in three cadavers in the dissecting-room materials. We hope that this paper will contribute to the clarification of the problem concerning the relation between the sciatic nerve and the piriformis muscle. 
Table 1. The data reported by previous workers on the relation of the sciatic nerve to the piriformis muscle, on which the common peroneal nerve passes out of the pelvis through the suprapiriformis foramen.

\begin{tabular}{|l||c|}
\hline Adachi (1900) & 2 Cases \\
Koganei et al (1903) & 1 Case \\
Adachi (1910) & 6 Cases \\
Miura (1932) & 1 Case \\
Yamagishi (1934) & 1 Case \\
Igarashi (1935) & 3 Cases \\
Beaton et al (1937) & 4 Cases \\
Kushida (1940) & 1 Case \\
Hashimoto et al (1942) & 14 Cases \\
Sugiyama (1943) & 2 Cases \\
Kobata (1949) & 2 Cases \\
Outi (1951) & 1 Case \\
\hline \hline Total & 38 Cases \\
\hline
\end{tabular}

\section{Observations}

Figs. 1, 3, 5, 7 and 9 are diagrams showing a dissection of the nerves in the gluteal region. Especially, Figs. 1, 3 and Figs. 5, 7 show the bilateral existence of the cases. As shown in Figs. 1, 3, 5,7 and 9 , in all cases the common peroneal nerve, the superior gluteal nerve and the inferior gluteal nerve pass out of the pelvis through the great sciatic foramen above the upper border of the piriformis muscle. The posterior femoral cutaneous nerve passes out of the pelvis through the great sciatic foramen partly above the upper border of the piriformis and partly below the piriformis muscle.

In Figs. 2, 4, 6, 8 and 10, the relation between the sacral plexus and the piriformis muscle is diagrammatically shown from the ventral side of the pelvis, as illustrated in Figs. 1, 3, 5, 7 and 9.

As clear in these figures, the common peroneal nerve derives from the dorsal branches of the anterior primary rami of the fourth and fifth lumbar and the first and second sacral nerves; (in Figs. 6 and 8 , of the fifth lumbar and the first and second sacral nerves).

The superior gluteal nerve receives fibers from the dorsal divisions of the fourth and fifth lumbar and the first sacral nerves; (in Fig. 6, of the fifth lumbar and the first sacral nerves, and in Fig. 8, of the fourth and fifth lumbar and the first and second 
sacral nerves).

The inferior gluteal nerve is formed by fibers from the dorsal divisions of the fifth lumbar and the first and second sacral nerves.

The dorsal portion of the posterior femoral cutaneous nerve stems from the dorsal branches of the anterior primary rami of the first and second sacral nerves; (in Fig. 8, of the second sacral nerve only), and the ventral portion of the posterior femoral cutaneous nerve receives fibers from the ventral branches of the anterior primary rami of the second and third sacral nerves; (in Figs. 6 and 8, of the second, third and fourth sacral nerves).

The tibial nerve is formed by fibers from the anterior divisions of the fourth and fifth lumbar and the first, second and third sacral nerves; and Figs. 6 and 8 show that the nerve is organized by fibers from the fifth lumbar and the first, second, third and fourth sacral nerves.

As can be seen in these figures, the nerves stemming from the dorsal divisions of the sacral plexus pass behind the piriformis muscle through the suprapiriformis foramen, and the nerves from the ventral divisions of the sacral plexus run over the ventral surface of the piriformis muscle and pass out of the pelvis at the lower border of the piriformis.

In our cases, the piriformis muscle arises from the front of the sacrum between the second and the fourth anterior sacral foraminae, separating the sacral plexus into the derivatives of the ventral and dorsal divisions of the nerves.

Recently, O u t i studied this subject and stated, that in the cases where the common peroneal nerve leaves the pelvic cavity by perforating the piriformis, the other fibers from the dorsal divisions of the sacral plexus also pass out of the pelvis by pirceing the piriformis.

Judging from our observations and $\mathrm{O} u$ ti's communications, it is highly probable, that the relation of the branches of the sacral plexus to the piriformis is similar to that of the branches of the lumbar plexus to the psoas muscle, and the fibers from the dorsal divisions which form the sacral plexus either perforate the piriformis or pass above the upper border of the piriformis. But contrary to the suggestion of $B$ eato $n$ et al the fibers from the ventral divisions which form the plexus will not pass out of the pelvis by running through the great sciatic foramen above the upper border of the piriformis. 


\section{Literature}

Adachi, B. (1900): Anatomische Unterșuchungen an Japanern. Zschr. f. Morphol. u. Anthropol., 2: 198.

Ad a ch i, B. (1910): Beiträge zur Anatomie der Japaner. XII. Die Statistik der Muskelvarietäten. Zschr. f. Morphol. u. Anthropol., $12: 262$.

Beaton, L.E. and Ans on, B.J. (1937): The relation of the sciatic nerve and its subdivisions to the piriformis muscle. Anat. Rec., $70: 1$.

Eisler, P. (1891): Der Plexus lumbosacralis des Menschen. Anat. Anz., 6: 274.

Fuk u m ot o, N. (1935): The sciatic nerve and the piriformis of Japanese. Fukuoka Ikadaigaku Zassi, $28: 756$. (Japanese.)

Fujita, T. (1957): Problem der Muskel-nervenverhaltnisse. Anthropol. Report, 2: 416. (Japanese.)

Hashimoto, M. and Sotoyama, K. (1942): Ueber die Lagebeziehungen des N. ischiadicus zum M. piriformis. Kaibogaku Zassi, $19: 171$. (Japanese.)

Ha y a ma, T. (1954): Relation of the sciatic nerve to the piriformis and its subdivisions. Nippon Daigaku Med. J., 13 : 1583. (Japanese.)

I gar a s i, J. (1935): On the relation of the sciatic nerve to the piriformis muscle. Studies from the Department of Anatomy, Faculty of Medicine, University of Kanazawa, 19: 123. (Japanese.)

Johnston, T.B. and Willis, J. (1949): The sacral plexus. Gray's Anatomy, 30 : 1146.

Kog a n e i, Y. (1903): Statistical observations of the muscle anomaly. Tokyo Igakkai Zassi, $17: 8$. (Japanese.)

Kobat a, T. (1949): Morphological relationship between the piriformis muscle and the sciatic nerve of the Japanese twins-fetus. The Anatomical Study on the Fetal Twins, $10: 63$. (Japanese.)

Kōno, T. (1929): Topographic anatomy of the gluteal region. Kaibogaku Zassi, 1: 47. (Japanese.)

K o n o, T. (1930): On the piriformis muscle. Kaibogaku Zassi, $2: 1017$. (Japanese.)

$\mathrm{K} \mathbf{u}$ bota, K., and et al (1957): A case of bilateral existence of ischiadic artery in man. Okajimas Folia Anat. Japon., $30: 339$.

Kushida, T. (1940): Ueber die Lumbosacralnerven die japanischen Feten. Kaibogaku Zassi, $16: 28$. (Japanese.)

Matsushima, M. (1927): Some anomaly cases of the muscles. Zicchi Ika To Rinsho, $4: 8$. (Japanese.)

Mi u ra, Y. (1932): Comparative anatomy of the gluteal muscles of the monozygotic fetal. twins. Part 1. Observations of the extra-gluteal muscles. Kaibogaku Zassi, 5. (Japanese.)

O u t, H. (1951): Morfologia studo priuru kazo de multapero de nervaj kaj muskolaj variocioj en anbau malsnpraj membroj. Kaibogaku Zassi (Acta Anat. Nippon.), $26: 32$. (Japanese.)

O u t i, H. (1952): Pri la rilatoj de la iskia plekso al la priforma muskolo. Kaibogaku Zassi (Acta Anat. Nippon.), $27: 69$. (Japanese.)

O u ti, H. (1956): pri la interrilato de la femura nervo kaj la psoas-muskolo ktp. Okajimas Folia Anat. Japon., 28 : 389.

O u t i, H. (1958): On some anomalies of muscles and nerves. Kaibogaku Zassi, $33: 9$ (Supplement). (Japanese.) 
Parson, F. G. and Ke ith, A. (1897): J. Anat., $31: 31$.

Paterson, A.M. (1894): The origin and distribution of the nerves to the lower lumb. J. Anat., $28: 84$.

Sch a f f er, J. P. (1953): Sacral plexus. Morris' Human Anatomy, $11: 1163$.

Shi in a, J. (1935): Morphological studies of the Ainu. Fukuoka Igaku Zassi, 24: 4. (Japanese.)

Sug i y a ma, J. (1943): Relationship between the sciatic nerve and the piriformis muscle of the Japanese monozygotic fetal twins. The Anatomical Study on the Fetal Twins, 4. (Japanese.)

Y a mag is hi, Y. (1934): A rare anomaly case of the origin of the sciatic nerve. Hokuetsu Igaku Zassi, 49 : 1137. (Japaniese:) 
Plate I

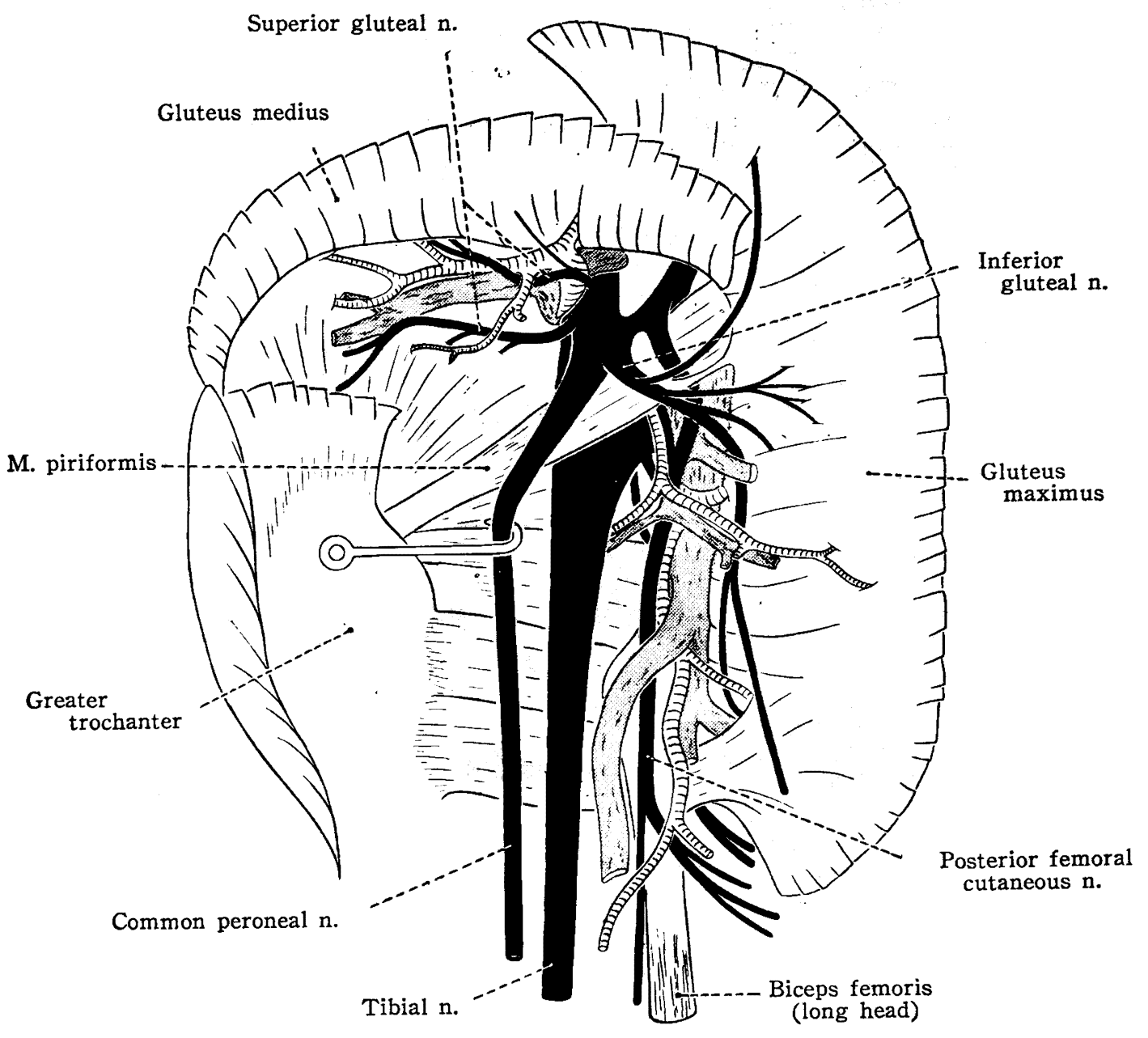

Fig. 1. A dissection of the nerves in the gluteal region. Dorsal view of the left side. 65-year old male. 
Plate II

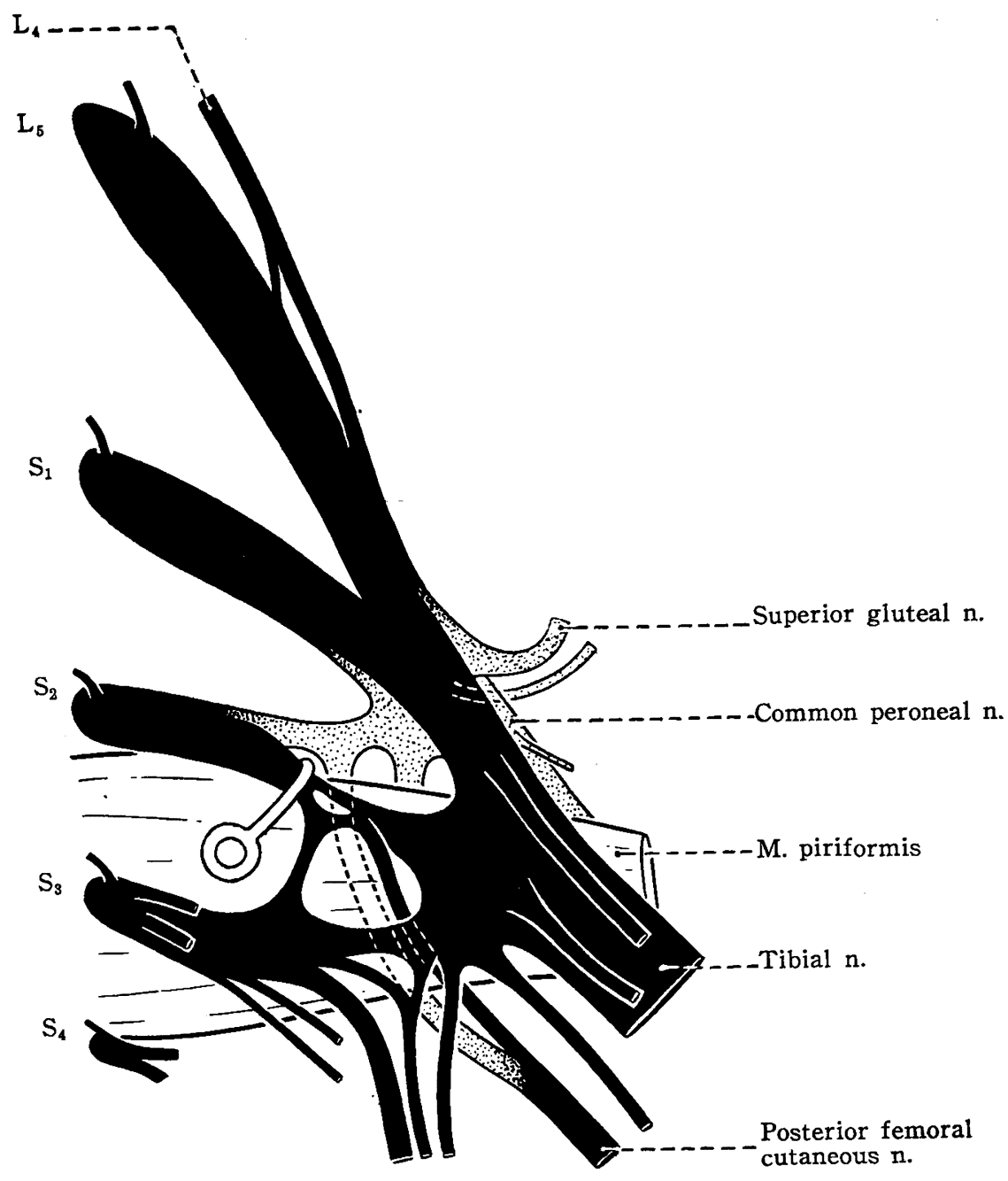

Fig. 2. A diagram showing the relation of the sacral plexus to the piriformis. The derivatives of the ventral divisions of the nerves are blackened, those of the dorsal divisions are shaded with dotts. Ventral view of the sacral plexus depicted in Figure 1. 
Plate III

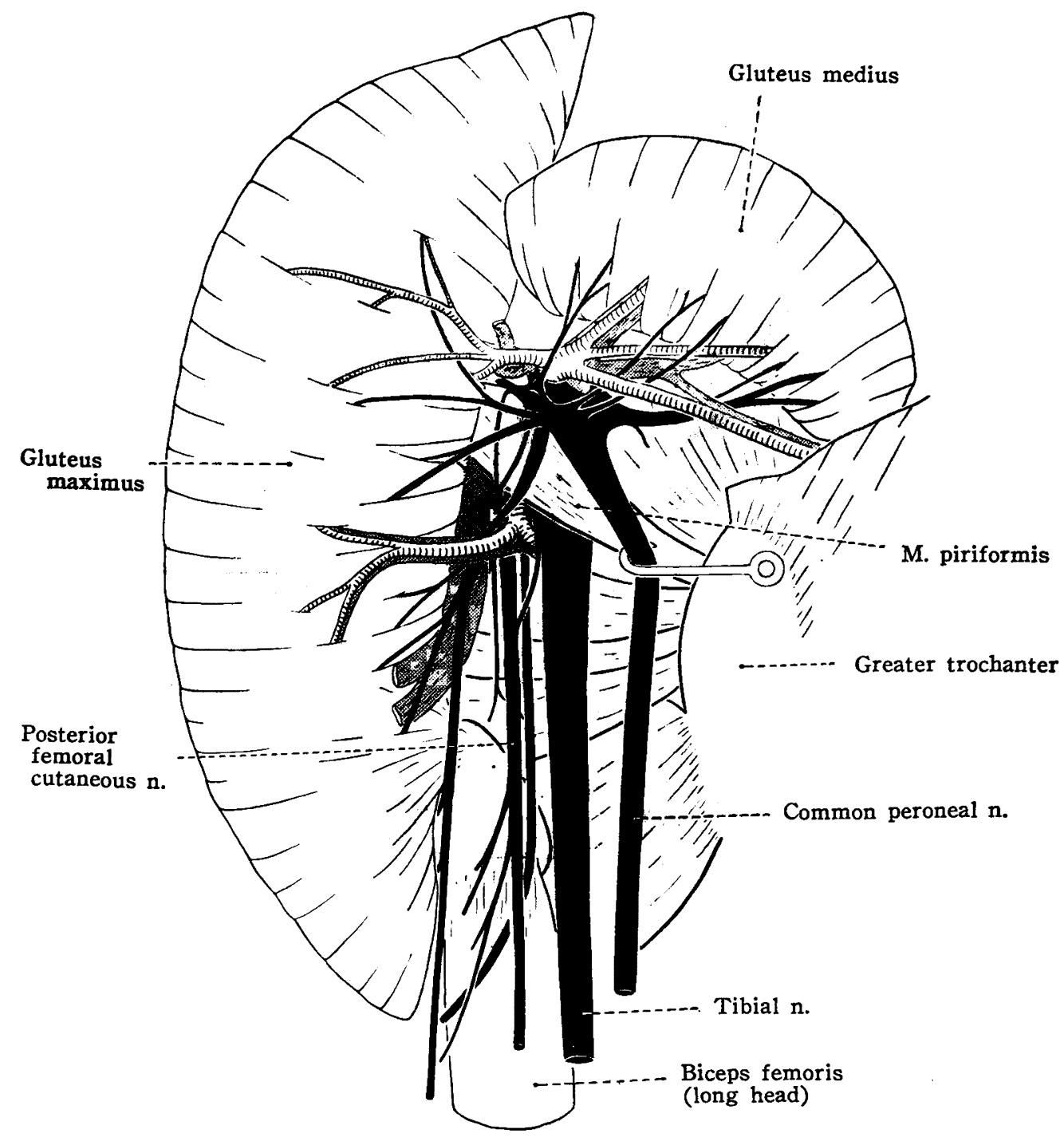

Fig. 3. A dissection of the nerves in the gluteal region. Dorsal view of the right side.165-year old male. 
Plate IV

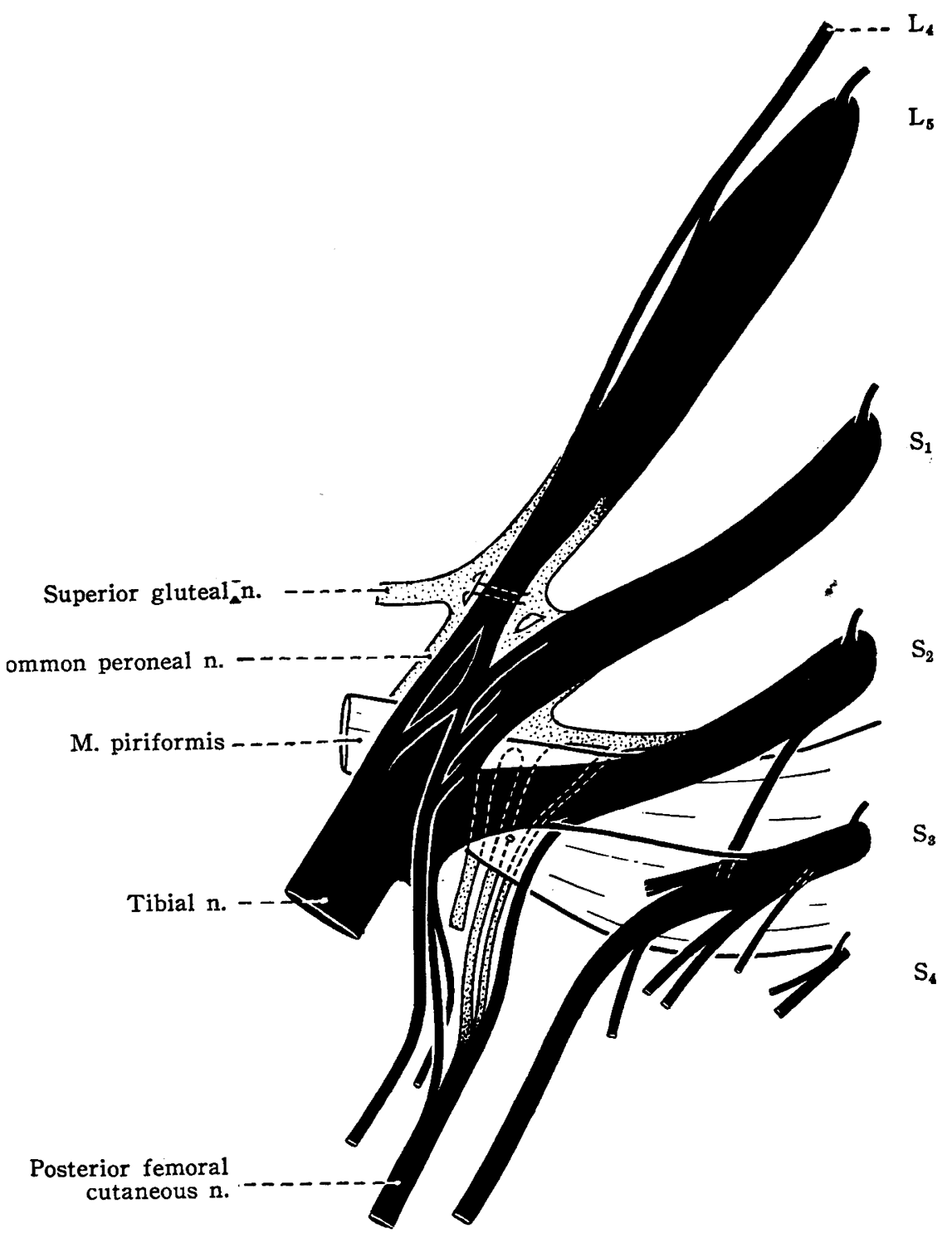

Fig. 4. A diagram showing the relation of the sacral plexus to the piriformis. The derivatives of the ventral divisions of the nerves are blackened, those of the dorsal divisions are shaded with dotts. Ventral view of the sacral plexus depicted in Figure 3. 
Plate V

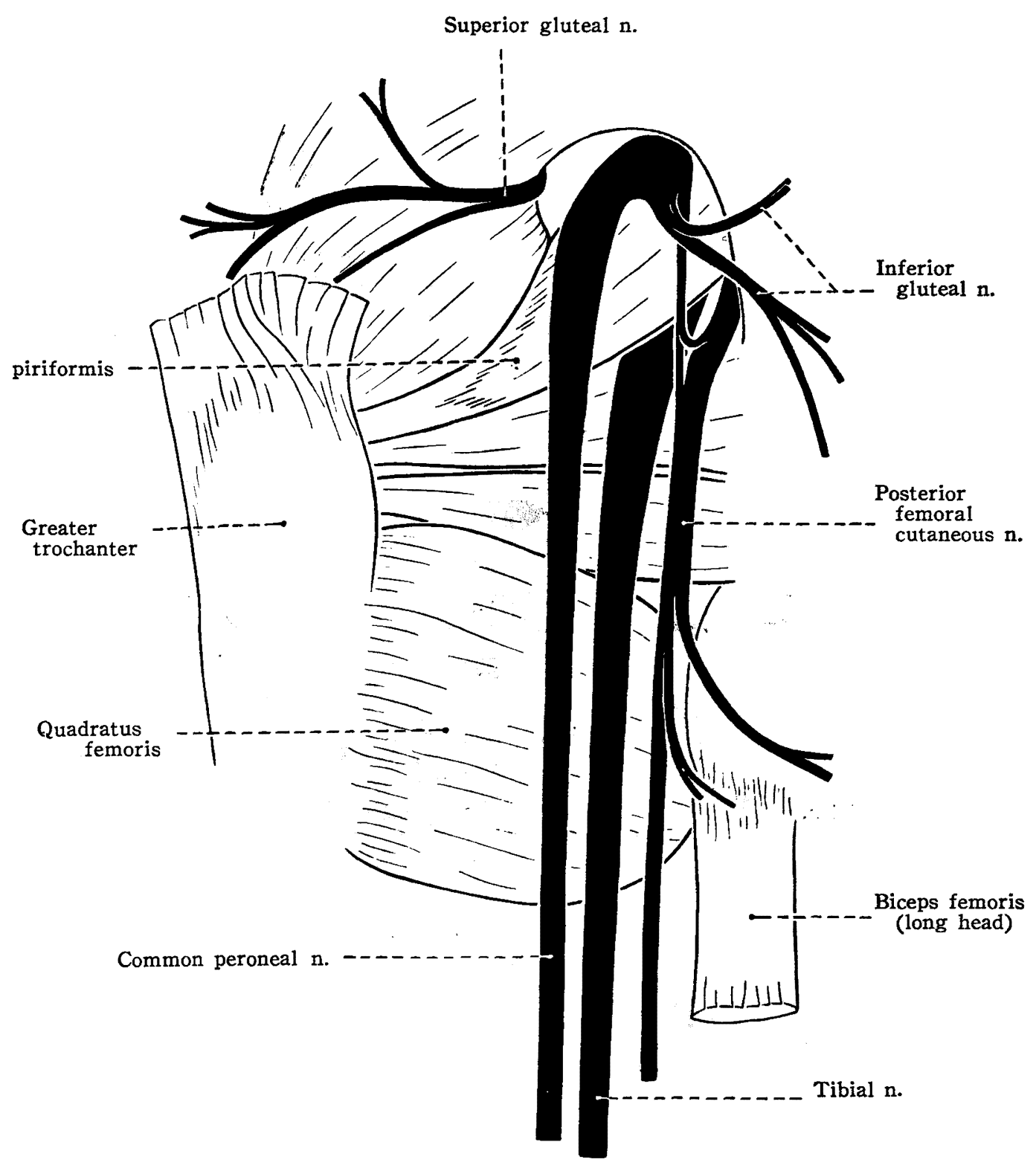

Fig. 5. A dissection of the nerves in the gluteal region. The gluteal muscles removed. Dorsal view of the left side. 52-year old male. 
Plate VI

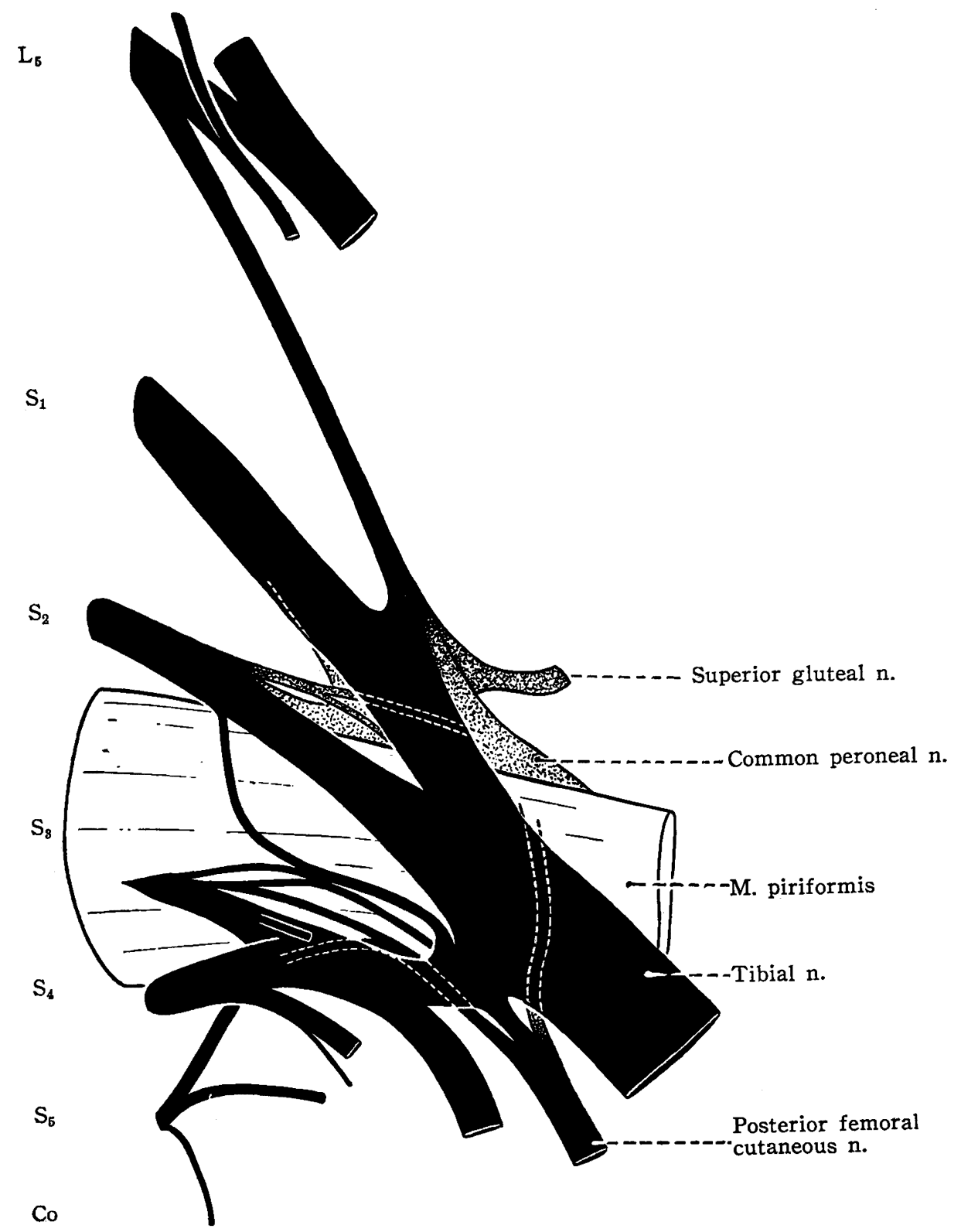

Fig. 6. Diagram of the relation of the sacral plexus to the piriformis. The ventral divisions and the nerves are blackened, the dorsal divisions and the nerves are shaded with dotts. Ventral view of the sacral plexus depicted in Figure 5. 


\section{Plate:VII}

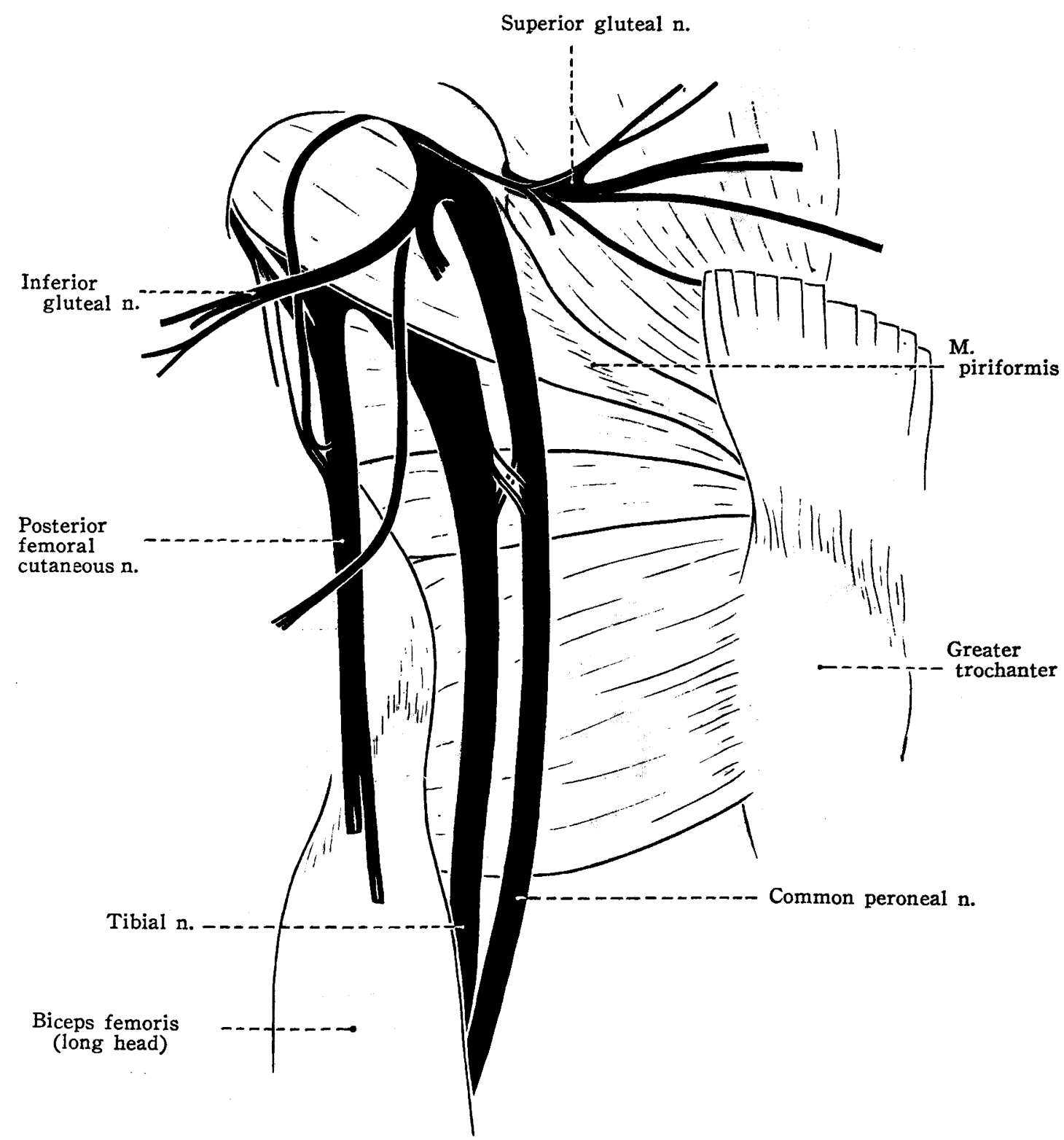

Fig. 7. Afdissection of the nerves in the gluteal region. The gluteal muscles removed. 52-yearyold:male. Dorsal view of the right side. 
Plate VIII

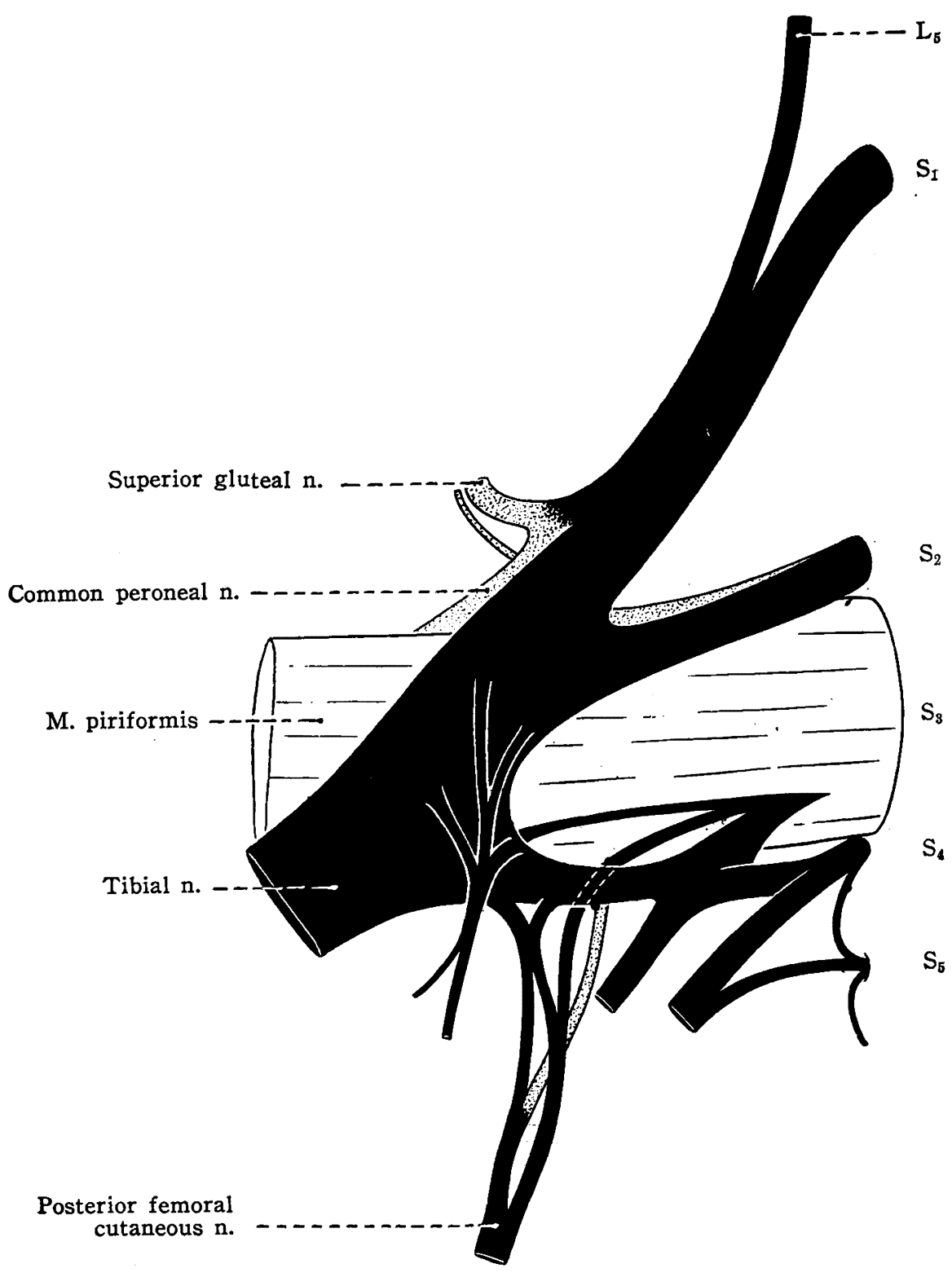

Fig. 8. Diagram of the relation of the sacral plexus to the piriformis. The ventral divisions and the nerves are blackened, the dorsal divisions and the nerves are shaded with dotts. Ventral view of the plexus depicted in Figure ?. 
Plate IX

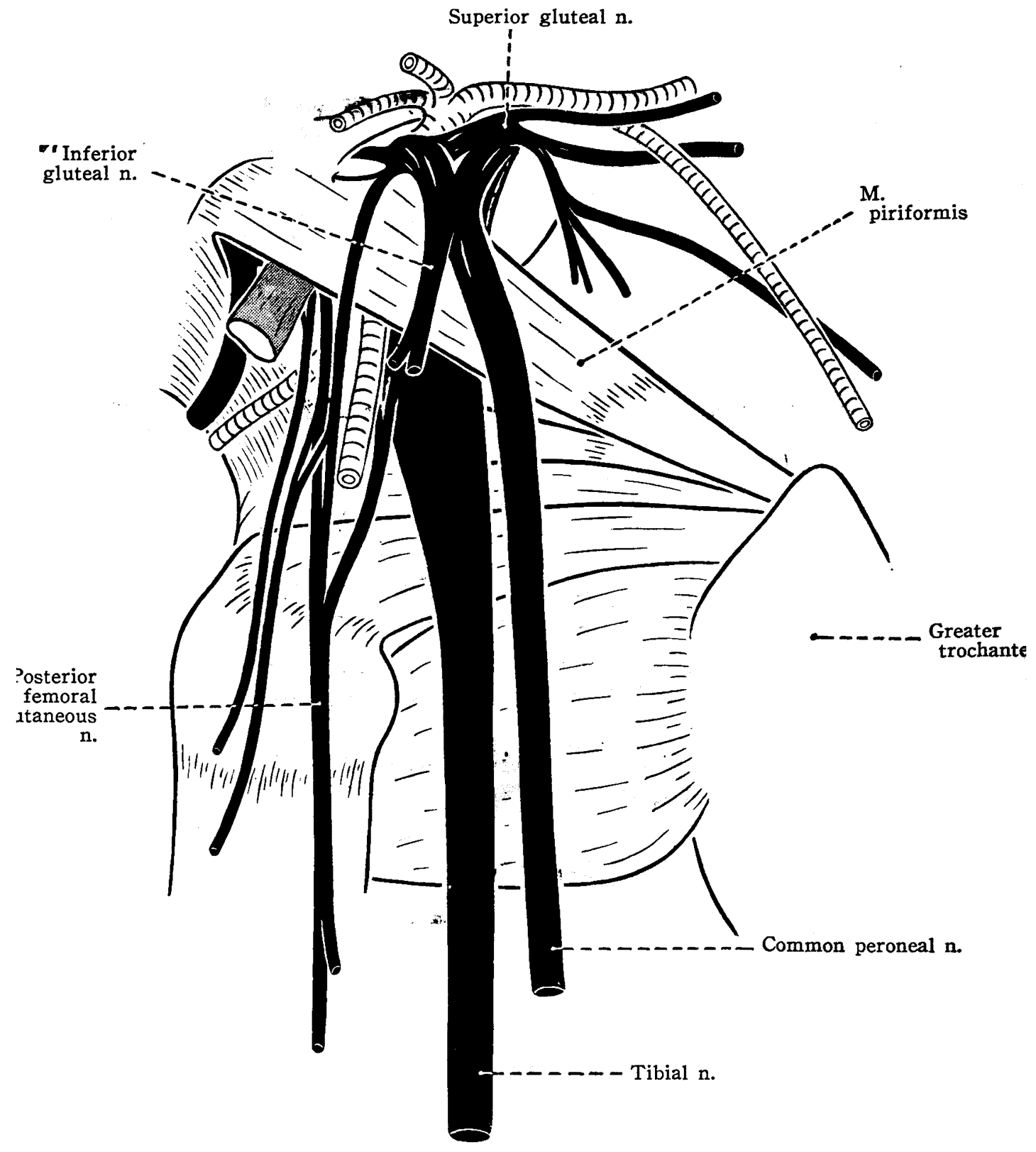

Fig. 9. A dissection of the nerves in the gluteal region. The gluteal muscles cut off. Dorsal view of the right side. About 35-year old female. 
Plate X

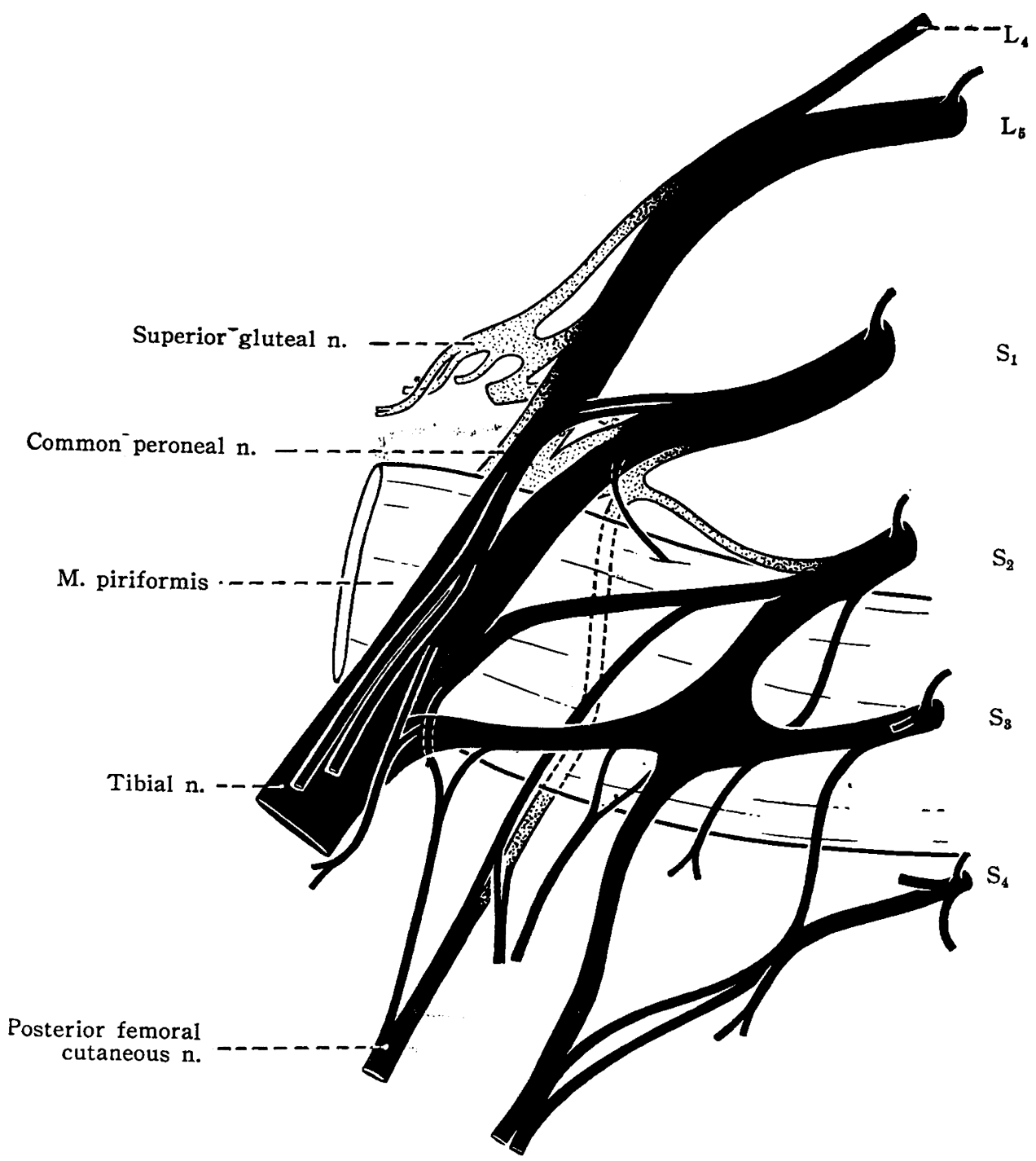

Fig. 10. The derivatives of the ventral divisions of the nerves are blackened, those of the dorsal divisions are shaded with dotts. Ventral view of the case depicted in Figure 9. 